\title{
Asthma in the elderly: The role of exhaled nitric oxide measurements
}

\author{
Michele Columbo a, ${ }^{\star}$, Bruce Wong ${ }^{\mathrm{b}}$, Reynold A. Panettieri Jrc ${ }^{\mathrm{c}}$, and Albert S. Rohra \\ a Asthma, Allergy and Immunology Specialists, 875 County Line Road, Bryn Mawr, PA 19010, \\ USA \\ b Center for Clinical Epidemiology and Biostatistics, University of Pennsylvania School of \\ Medicine, 423 Guardian Drive, Philadelphia, PA 19104, USA \\ c Pulmonary, Allergy and Critical Care Division, University of Pennsylvania School of Medicine, \\ 125 South 31st Street, Philadelphia, PA 19104, USA
}

\section{Summary}

Asthma in the elderly is poorly understood because only a small minority of asthma studies have investigated this patients group. Fractional Exhaled Nitric Oxide (FENO) has been extensively studied in children and adults with asthma, but little is known about FENO in elderly asthmatics. We studied the role of serial measurements of FENO in elderly subjects with asthma.

Thirty stable asthmatics 65 years old and older were followed for one year with evaluations at baseline and every three months. We looked for associations between FENO and subjects' demographics, comorbidities, asthma treatment, spirometric values and Asthma Control Test (ACT) scores. FENO was not elevated in our study subjects throughout the study period (mean < $30 \mathrm{ppb}$ ). FENO significantly increased and FEV1\% decreased between first and last study visit, while ACT scores and steroid dose remained unchanged. No significant correlation was found between FENO and FEV1/FVC, other spirometric values, inhaled steroid dose or ACTscores at any time point. No associations of FENO were found with age, sex, Body Mass Index (BMI), atopic status, disease duration, presence of rhinitis or gastroesophageal reflux disease (GERD), or other medications used. Moderate asthma exacerbations did not consistently cause an increase of FENO.

In stable elderly asthmatic patients, FENO was not elevated and did not correlate with subjects' demographics, comorbidities, treatment, symptoms or spirometric values. Routine measurements of FENO may not be clinically valuable in elderly asthmatics.

\section{Keywords}

Asthma; FENO; Elderly

\footnotetext{
(C) 2013 Elsevier Ltd. All rights reserved.

* Corresponding author. 875 County Line Road, Suite 107, Bryn Mawr, PA 19010, USA. Tel.: +1 610527 2000; fax: 15256772. michelecolumbo@msn.com (M. Columbo)..

Conflict of interest statement

None of the authors has a conflict of interest regarding the content of this article.
} 
People older than 65 years of age are a rapidly growing demographic group and will account for over $20 \%$ of the U.S. population by the year $2050 .{ }^{1}$ Most studies on asthma have not included elderly asthmatics who are more likely to be underdiagnosed, undertreated, and hospitalized when compared to their younger counterparts. ${ }^{1}$ Pulmonary function tests and monitoring asthmatic symptoms may be less reliable in the elderly because of other potential causes of respiratory impairment and delayed awareness of bronchoconstriction. Elderly asthmatics have an increased mortality compared to their non-asthmatic counterparts. ${ }^{1}$

FENO has been proposed as a marker of airway eosinophilic inflammation, but the role of FENO measurements in patients with asthma remains unclear. To our knowledge, no study has addressed the value of serial FENO measurements in older asthmatics. Therefore, we performed such measurements every three months for one year in a group of elderly, stable asthmatic patients. We looked for associations between FENO and subjects' demographics, comorbidities, asthma treatment, spirometric values and ACT scores.

Thirty subjects 65 years old and older with asthma followed in an Allergy and Immunology practice in suburban Philadelphia were included in the study. Twenty-five study subjects were lifetime nonsmokers and five smoked for less than 10 pack-years. The study was approved by the Main Line Hospitals Institutional Review Board.

The presence of atopy was verified by allergy skin tests. Spirometric values were obtained by KoKo Spirometer (nSpire Health, Inc, Longmont, CO). FENO was measured online in triplicate determinations by NIOX MINO (Aerocrine, New Providence, NJ) according to the ATS/ERS guidelines and reported in ppb as the mean of the three values.

Statistical analysis was performed using STATA v10 (College Station, TX). Descriptive variables were expressed as means and standard deviation, Multiple linear regression was used to test association between groups of variables and group differences were tested using unpaired t-tests. Significance was accepted at alpha Z 0.05 with no adjustment for multiple comparisons.

Table 1 shows the study subjects' characteristics at baseline. We found that FENO was not elevated (mean $<30 \mathrm{ppb}$ at each of the four study visits) and there were no significant differences between any of the values of $\mathrm{FENO}, \mathrm{FEV}_{1} \%$ and ACT scores at each study visit and the ones obtained at the previous visit. However, there was a significant increase in FENO (to $27 \pm 14.5 \mathrm{ppb}, \mathrm{p}=0.02$ ) and a decrease of the $\mathrm{FEV}_{1 \%}$ (to $71.3 \pm 15.8 \%, \mathrm{p}=$ $0.005)$ between the first and the last visits, while ACT scores (22.1 \pm 2.8 vs. $22.3 \pm 3.3)$ and inhaled steroid dose ( $353 \pm 363$ vs. $375 \pm 374 \mathrm{mcg} /$ day $)$ were unchanged.

We found no association between FENO and age, sex, BMI, atopic status, disease duration, rhinitis, or GERD ( $p>0.34$ for all measurements).

We found no association between FENO and inhaled steroid dose, treatment with a longacting bronchodilator, leukotriene antagonist, or nasal steroid ( $p>0.18$ for all measurements). FENO was higher in the subjects who were not receiving inhaled steroids ( $36.8 \pm 16.1$ vs. $24.2 \pm 19.2 \mathrm{ppb}$, visit $3, \mathrm{n}=6$ and 24 , respectively), whereas ACT (20.8 vs. 
21.3) and $\mathrm{FEV}_{1 \%}(71.9 \%$ vs. $73.5 \%)$ were unchanged. This difference did not reach statistical significance $(\mathrm{p}=0.11)$, possibly due to the small number of untreated subjects.

We found no association between FENO and ACT scores or spirometric values, except for $\mathrm{FEV}_{1 \%}$ and $\mathrm{FEF}_{25 \mathrm{e} 75 \%}$ at visit $2(\mathrm{p}<0.04)$. When ACT scores were $\unlhd 9(17.2 \pm 1.5, \mathrm{n}=5)$, FENO was low $\left(11.6 \pm 3.9 \mathrm{ppb}\right.$ ) and the $\mathrm{FEV}_{1 \%}$ was $91.6 \pm 24.4 \%$ (steroid dose $712 \pm 557$ $\mathrm{mcg} /$ day). When the $\mathrm{FEV}_{1}$ was $<80 \%(\mathrm{n}=12)$, FENO was similar as compared to when it was $>80 \%(17.2 \pm 11$ vs. $18.9 \pm 16.2 \mathrm{ppb}$, respectively, $\mathrm{p}=0.73)$.

A few moderate asthma exacerbations occurred during the study period (8 out 120 study visits, mean steroid dose $316 \pm 493 \mathrm{mcg} /$ day). At the time of these exacerbations the ACT scores were significantly lower compared to the prior visit (13.3 \pm 4.9 vs. $21.4 \pm 4, \mathrm{p}<$ 0.02). FENO ( $34.5 \pm 29$ vs. $24.8 \pm 14.7$ ppb) and FEV $_{1 \%}(69 \pm 13 \%$ vs. $76.6 \pm 23.4 \%)$ showed a trend for increase of FENO and decrease of the FEV1\%, but these did not reach statistical significance ( $\mathrm{p}>0.19$ for both).

Neither the baseline data, nor the results of the analysis of associations were affected by limiting the statistical analysis to the lifetime non smokers (data not shown).

Our results showing that FENO is not elevated in elderly asthmatics are in agreement with a very recent study in elderly asthmatics half of whom were on inhaled steroids whose FENO was about $20 \mathrm{ppb}^{2}$ We did not find an association between FENO and subjects' demographics including age or with atopic disease as in a recent study that found similar FENO levels in older and younger asthmatic adults. ${ }^{3}$ However, in another report FENO was positively associated with the number of positive skin tests. ${ }^{4}$

In adult asthmatics, FENO was found to be negatively but weakly associated with the inhaled steroid dose. ${ }^{5}$ In contrast, in elderly asthmatics we did not find an association between FENO and steroid dose or other anti-asthmatic drugs. However, we cannot rule out that in our subjects inhaled steroids may inhibit FENO independent of their dose.

In adult patients with asthma, FENO has been negatively, but weakly associated with ACT scores $^{6}$ and inconsistently with lung function. In our elderly subjects, FENO was not associated with ACT scores or with spirometric values except at visit 2. Our results are in agreement with a very recent study in younger asthmatics on inhaled steroids. ${ }^{7}$

Only a few moderate asthma exacerbations occurred during the study period. While FENO increased and $\mathrm{FEV}_{1 \%}$ decreased, these values did not reach statistical significance, possibly because of the small number of observations. However, a very recent study in adult subjects on inhaled steroids similarly showed that FENO does not consistently increase during severe asthma exacerbations. $^{8}$

Limitations of our study include the relatively small number of subjects, almost exclusively caucasians, and that most subjects were well controlled on inhaled steroids. However, our results are in agreement with several recent studies and our study schedule reproduces a relatively typical "real life" clinical scenario. 
In conclusion, our study shows that in stable elderly asthmatics on inhaled steroids FENO is not elevated and routine measurements of FENO may not be clinically valuable. Our results need confirmation in larger cohorts of elderly asthmatics including subjects untreated with inhaled steroids and those experiencing severe exacerbations.

\section{Acknowledgments}

This study was funded by The Sharpe-Strumia Research Foundation of Bryn Mawr Hospital, Bryn Mawr, PA (SSRF 2009-03 and 2010-10). The study sponsor played no role in the study design, analysis, interpretation, in the writing of the manuscript, or in the decision to submit it for publication.

\section{References}

1. Hanania NA, King MJ, Braman SS, et al. Asthma in the elderly: current understanding and future research needs - a report of a National Institute on Aging (NIA) workshop. J Allergy Clin Immunol. 2011; 128:S4-24. [PubMed: 21872730]

2. Smith AM, Villareal M, Bernstein DI, Swikert DJ. Asthma in the elderly: risk factors and impact on physical function. Ann Allergy Asthma Immunol. 2012; 108:305-10. [PubMed: 22541399]

3. Hardaker KM, Downie SR, Kermode JA, Farah CS, Brown NJ, Berend N, King GG, Salome CM. Predictors of airway hyper-responsiveness differ between old and young patients with asthma. Chest. 2011; 139:1395-401. [PubMed: 21454398]

4. Craig TJ, King TS, Lemanske Jr RF, Wechsler ME, Icitovic N, Zimmerman RR, Wasserman S. Aeroallergen sensitization correlates with $\mathrm{PC}_{20}$ and exhaled nitric oxide in subjects with mild-tomoderate asthma. J Allergy Clin Immunol. 2008; 121:671-7. [PubMed: 18234311]

5. Menzies D, Jackson C, Mistry C, Houston R, Lipworth BJ. Symptoms, spirometry, exhaled nitric oxide, and asthma exacerbations in clinical practice. Ann Allergy Asthma Immunol. 2008; 101:248-55. [PubMed: 18814447]

6. Shirai T, Furuhashi K, Suda T, Chida K. Relationship of the asthma control test with pulmonary function and exhaled nitric oxide. Ann Allergy Asthma Immunol. 2008; 101:608-13. [PubMed: 19119704]

7. Zeiger RS, Schatz M, Zhang F, Crawford WW, Kaplan MS, Roth RM, Chen W. Elevated exhaled nitric oxide is a clinical indicator of future uncontrolled asthma in asthmatic patients on inhaled corticosteroids. J Allergy Clin Immunol. 2011; 28:412-4. [PubMed: 21807253]

8. Gelb AF, Mondzadeh R, Singh DH, Fraser C, George SC. In moderate-to-severe asthma patients monitoring exhaled nitric oxide during exacerbation is not a good predictor of spirometric response to oral corticosteroid. J Allergy Clin Immunol. 2012; 129:1491-8. [PubMed: 22560478] 


\section{Table 1}

Subjects' characteristics at baseline.

\begin{tabular}{ll}
\hline Female/male & $18 / 12$ \\
Age, yr (range) & $71.6 \pm 4.9(65-84)$ \\
BMI (range) & $25.6 \pm 3.8(19-34)$ \\
Atopy & $21 / 30$ \\
Duration of disease, yr (range) & $35 \pm 20.3(2-70)$ \\
Inhaled steroids (dose) & $26 / 30(384 \pm 378$ mcg/day) \\
Long acting bronchodilator & $20 / 30$ \\
Leukotriene antagonist & $11 / 30$ \\
Theophylline & $2 / 30$ \\
Prednisone & $2 / 30$ \\
Inhaled anticholinergic & $1 / 30$ \\
Nasal steroids & $15 / 30$ \\
Rhinitis & $27 / 30$ \\
Nasal polyps $_{\text {GERD }}$ & $2 / 30$ \\
Heart disease & $12 / 30$ \\
ACT score & $3 / 30$ \\
FENO (ppb) $_{\text {FEV }}$ (\%) & $22.1 \pm 2.8$ \\
FEV $/$ FVC & $18.2 \pm 14.3$ \\
FEF $_{25-75 \%}$ & $84.9 \pm 20.3$ \\
\hline
\end{tabular}

Results are expressed as the mean \pm S.D. Of the two subjects on prednisone at baseline, in one it was discontinued shortly after the initial visit, in the other it was reduced from $10 \mathrm{mg} /$ day to $2.5 \mathrm{mg} /$ day for the rest of the study period. 